\title{
Thermodynamic Performance of Pressurized Water Reactor Combined with Fossil-Fuel Superheater
}

Andhika Feri Wibisono*, Eugene Shwageraus

Department of Engineering, University of Cambridge, CB2 1PZ Cambridge, United Kingdom

\begin{abstract}
It is known that the Pressurized Water Reactors (PWRs), which are the most common type of nuclear reactor existing today, usually used to provide a base load electricity. In order to be able to compete with other generation types (fossil and renewables), it would be desirable to enable PWRs with a load following capabilities to cope with varying electricity demand, especially in deregulated markets.

The thermal efficiency of PWRs can be increased by fitting the power plant with conventional fossil fuel superheaters. This hybrid system has been hypothesised to be able to adjust the power output and the cycle efficiency of PWRs. Such mode of operation would also improve the efficiency of converting the fossil fuel heat because it is applied only at the superheater stage. There are several ways to supply the heat to the superheaters, for example, by using the exhaust gas from the gas turbines and using the conventional gas burner.

In this paper, the thermodynamic performance of the hybrid systems (PWR with superheater) is investigated for large reactor and Small Modular Reactor (SMR) application. The thermal efficiency of the AP1000 can be improved from 30.2\% to $45.8 \%$ (with CCGT), $35.6 \%$ (with gas burner), and $36.6 \%$ (gas burner with reheating). The thermal efficiency of the SMR can be improved from $33.4 \%$ to nearly $45 \%$ (with CCGT), $35.5 \%$ (with gas burner), and $37.4 \%$ (gas burner with reheating). The analysis results show that it is possible for the hybrid system to operate between $65 \%$ and the full power load.
\end{abstract}

Keywords: Pressurized Water Reactors, Superheater, Thermal Efficiency, Load Following, Small Modular Reactor.

\section{Introduction}

Nuclear power is a favourable source for providing a base load of electricity due to its stable power supply, high capital costs while relatively small fuel costs. However, the electricity demand is not fixed but varies daily, weekly and seasonally. In order to be able to compete economically with other energy sources, especially in deregulated markets, it is desirable for the nuclear power plant to develop a load following capabilities [1]. The Pressurized Water Reactor (PWR) is the most common nuclear reactor type. It currently makes up around $70 \%$ of nuclear reactor fleet in the world. However, PWRs have relatively low thermal efficiency compared to that of modern fossil fueled power plants. Coal power plant efficiency can reach up to $42 \%$ and gas turbine can reach up to $40 \%$ and even $60 \%$ if it is combined with a bottoming steam cycle (combined cycle). The low thermal efficiency of the PWR is a result of the steam in PWR being generated at a near saturated condition which limits the temperature of heat addition as boiling in the primary coolant has to be avoided.

One way to develop a PWR with a better load following scheme is to produce superheated steam, which has several benefits in the Rankine cycle [2]. First of all, the use of superheated steam can improve turbine performance. The lifetime of a turbine is limited by water droplet formation which erode the turbine blades. Superheating of steam reduces the steam wetness thus improving the lifetime of steam turbine. Secondly, superheated steam also improves the thermodynamic efficiency of the Rankine cycle as it increases the average temperature of the heat addition.

* Corresponding author. Tel.: +44 1223332887

E-mail address: afw36@cam.ac.uk 
Superheated steam in a PWR can be produced by further heating the saturated steam with a superheater. This superheater can either be powered by another nuclear reactor or by fossil fuels. By combining a PWR with a conventional superheater, the economics of the system has the potential to be improved. The hybrid system allows full utilization of nuclear heat source, which is a low-operating-cost base-load system, with peak power production using low-capital-cost fossil heat [1]. The nuclear heat is used to generate the saturated steam while the fossil heat is used to superheat the steam, which suggests that the hybrid system use the fossil heat more efficiently than the conventional fossil power plant. The load following that can be achieved without affecting the nuclear reactor operation and the additional heat supplied from the fossil fuel would result in improvement of the power conversion efficiency throughout the system operation. The scope of this paper is to further investigate the combination scheme of PWR with fossil-fueled superheater in order to develop a PWR system with a load following capability. The thermodynamic performance of the hybrid system (PWR with conventional superheater) is investigated for large reactor and Small Modular Reactor (SMR) application.

\section{Superheating and Combined Cycle Concept}

The concept of superheating the steam in LWR is not a new idea. It has been implemented in several nuclear reactors in the past. Indian Point 1 (USA), Garigliano (Italy), and Lingen (Germany) are examples of nuclear power plants with secondary reheating powered by oil. The performance of the combined cycle was questionable due to low load factor and material failures. It is however, quite reasonable to reconsider this concept as the technology of thermal power plants, nuclear and conventional, has become more reliable than it was back in 1960s [3].

Forsberg and Conklin [1] proposed a hybrid power cycle by coupling the Advanced HighTemperature Reactor (AHTR) with the Combined Cycle Gas Turbine (CCGT). During low electricity demand, the nuclear heat from AHTR could provide an adequate supply for baseload electricity with the CCGT. When the demand is high, further heating of the air in the gas turbine could be done by conventional combustor fueled by natural gas. Although the AHTR is a different type of reactor from the LWR, their study shows that nuclear power can be more competitive when it is coupled with a conventional heater as it can produce low-cost baseload electricity and lower-cost peak power relative to the existing combination of base-load nuclear power plant and fossil-fired peak electricity production.

Darwish et al. [4] investigated the thermal performance of the PWR nuclear reactor AP600 combined with existing gas turbines in Kuwait. The results of their study show that this combination scheme could increase the nuclear power plant (NPP) power output from 607 MWe to 1,151.4 MWe. The power cost of the modified AP600 was predicted to be $\$ 49.83 / \mathrm{MWh}$, which was less by $45.6 \%$ than that of Gas Steam Turbine Combine Cycle (GSTCC) power plant (\$91.6/MWh).

Zaryankin et al. [5] studied the hybrid nuclear power plant (WWER-1000) with fossil fuel superheater (gas combustor technology) and found that the hybrid nuclear power plant could increase the power generation from 1,000 MWe to 2,050 MWe with an efficiency increase of $8 \%$. The designed external steam superheater enables an increase in steam temperature from $274{ }^{\circ} \mathrm{C}$ to $600{ }^{\circ} \mathrm{C}$.

Most previous studies in the area of hybrid nuclear system with fossil fuel superheater $[4,5]$ focused on the improvement of the cycle efficiency. Darwish et al. [4] utilizes the heat from a 
gas turbine while Zaryankin et al. [5] uses the conventional gas burner. In this paper, both schemes of coupling are considered and compared. In addition, the reheating method was investigated to further improve the cycle efficiency. Finally, the hybrid system heat balance was modified to show that it has the capability of load following without affecting the reactor operation.

\section{AP1000 Steam Cycle}

The nuclear power plant used as a reference in this study is the AP1000. It is a PWR designed by Westinghouse which produces about 1100 MWe. A schematic diagram of AP1000 steam cycle based on its plant description [6], is shown in Fig. 1. The heat from the primary loop is used to generate steam in the steam generator (SG). This steam then enters the turbine after some portion is extracted to provide heat for the Moisture Separator \& Reheater (MSR). The AP1000 turbine consists of a double-flow, high-pressure (HP) cylinder and three doubleflow, low-pressure (LP) cylinders. The steam conditions at the inlet of HP cylinder are 55 bar and $271{ }^{\circ} \mathrm{C}$. Some portion of the steam is extracted from the HP turbine to provide heat to MSR and High Pressure Feedwater Heater. The HP turbine outlet then goes through the MSR to be dried before entering the LP turbine. Some portion of the steam is again extracted from the LP turbine to provide heat to the Low Pressure Feedwater Heaters. The outlet steam from the LP turbine is condensed before being pumped and heated as a feedwater for the steam generator [6]. The conditions at each point in Fig. 1 are reported in Table 1.

Fig. 1. AP1000 steam cycle flow diagram.

Table 1. Steam (Water) Condition in Each Point of AP1000 Steam Cycle

The heat produced from the reactor is used for generating the steam in the Steam Generator (SG) by following Eq. (1) while the steam expansion process inside the turbine follows Eq. (2) and Eq. (3). The heat rejection in the condenser can be calculated by Eq. (4). The pumping work can be calculated by Eq. (5) and Eq. (6) and the feedwater heater process is following Eq. (7). The electricity produced by generator is calculated from Eq. (8). The isentropic efficiencies of the assumed turbine, pump and generator efficiencies are based on the values reported by Ion and Codrut [7] and shown in Table 2. The energy balance calculation is done using X Steam Table software version 2.6 [8] which was developed based on the revised data from the International Association for the Properties of Water and Steam (IAPWS) Industrial formulation 1997 [9].

$$
\begin{aligned}
& Q_{S G}=\dot{m}_{\text {steam }}\left(h_{S G, \text { out }}-h_{S G, \text { in }}\right) \\
& \Delta h_{\text {Turbine }}=\eta_{\text {Turbine }} \Delta h_{\text {Turbine,isentropic }} \\
& W_{\text {Turbine }}=\dot{m}_{\text {steam }} \Delta h_{\text {Turbine }} \\
& Q_{\text {Cond }}=\dot{m}_{\text {steam }}\left(h_{\text {Cond,in }}-h_{\text {Cond,out }}\right) \\
& \Delta h_{\text {Pump }}=\Delta h_{\text {Pump,isentropic }} / \eta_{\text {Pump }} \\
& W_{\text {Pump }}=\dot{m}_{\text {feedwater }} \Delta h_{\text {Pump }} \\
& \dot{m}_{\text {feedwater }} \Delta h_{\text {feedwater }}=\dot{m}_{\text {steam }} \Delta h_{\text {steam }} \\
& P=\eta_{\text {Generator }} W_{\text {Turbine }}
\end{aligned}
$$

Table 2. Steam Cycle Equipment Efficiencies [7]

\section{Coupling of AP1000 with Fossil-Fueled Superheater}


The thermal efficiency of AP1000, which is about $30.23 \%$, is quite low compared to the conventional thermal power plants. As mentioned earlier, this low thermal efficiency can be improved by using the superheater to increase the generated steam temperature. There are two schemes considered in this work for such combination. The first scheme couples the AP1000 Rankine cycle with a generic gas turbine cycle. In this coupling scheme, the exhaust gas from a gas turbine is used to super heat the steam. The gas turbine SGT5-4000F designed by Siemens is used for this study as a reference due to considerable experience of its use in CCGT. The exhaust temperature of this gas turbine is $577{ }^{\circ} \mathrm{C}$ and its exhaust gas flow rate is $692 \mathrm{~kg} / \mathrm{s}$ at full power [10]. The properties of air needed for the thermodynamic analysis were taken from Lemmon et al. [11].

The other coupling scheme considered using a combustor fueled by natural gas. In this coupling scheme, the steam can reach higher temperature than in the scheme which uses the gas turbines exhaust gas. However, the superheated steam temperature is limited by the existing steam turbine maximum operating temperature take as $600{ }^{\circ} \mathrm{C}$ in this study. The steam cycle flow diagram of AP1000 with the conventional superheater is displayed in Fig. 2. The results of the thermodynamic analysis of both coupling schemes are shown in Table 3. The total cycle efficiency was calculated from Eq. (9) while the fossil fuel cycle efficiency is calculated from Eq. (10).

$\eta_{\text {Total }}=\frac{P_{\text {Total }}}{Q_{\text {Nuclear reactor }}+Q_{\text {Fossil fuel }}}$
$\eta_{\text {Fossil heat }}=\frac{P_{\text {Total }}-P_{\text {Nuclear without superheating }}}{Q_{\text {Fossil fuel }}}$

Fig. 2. AP1000 steam cycle with superheater flow diagram.

Table 3. Thermodynamic Analysis Results of AP1000 with Superheater

In the coupling scheme of the AP1000 with the conventional superheater, the steam generated in SG is further heated to superheated condition before entering the HP turbine. This coupling scheme can eliminate the MSR and reduce the stage of the Feedwater Heater as the same heat source can also be used in the Economizer to heat the feedwater before entering the SG. Therefore, the thermodynamic performance of the plant can be improved as the steam portion and steam quality entering the turbine is better. This improvement in thermodynamic performance can be observed by comparing the T-s diagram shown in Fig. 3. The reference points shown in the T-s diagram correspond to those specified in Fig. 1 and 2.

Fig. 3. T-s diagram of AP1000 steam cycle: (a) without superheater; (b) with superheater.

Table 3 shows that the superheater can improve thermal efficiency of the AP1000. By using exhaust gas from gas turbine to produce superheated steam, the cycle efficiency of AP1000 can be increased from $30.23 \%$ to $45.78 \%$ while the conventional gas burner helps to increase cycle efficiency to $35.66 \%$. In addition, the power generated by the nuclear steam cycle can be doubled when the AP1000 is coupled with a superheater, which is consistent with the result of the study done by Zaryankin et al. [5]. There is a significant increase in the amount of power generated because the superheater increases the amount of heat stored in the steam by bringing the steam to superheated condition. Also, the removal of the MSR from the plant increases the mass flow of steam that can be expanded in the steam turbine (AP1000 extracts about $30 \%$ of steam from the HP turbine to provide heat for the MSR). 
The increase in total thermal efficiency by using CCGT scheme is quite significant and is comparable to the thermal efficiency of the fossil fueled power plant while the total efficiency of gas burner scheme concept is less significant. However, one can argue that besides total thermal efficiency, the fossil fuel cycle efficiency, which is calculated by dividing the additional electric power by the additional heat supplied to the system, is also an important aspect to be considered in the performance analysis of this superheater concept. The CCGT concept can provide a fossil fuel cycle efficiency value of $56.19 \%$, a significant increase compared to the stand alone gas turbine thermal efficiency (approximately 40\%) and it is even comparable to the existing commercial combined cycle gas turbine (CCGT) thermal efficiency, which can reach up to $60 \%$. The fossil fuel cycle efficiency of the gas burner concept is about $43.66 \%$. Although this value is smaller compared to CCGT thermal efficiency performance, it is above the existing commercial stand-alone gas turbine thermal performance. Therefore, it can be concluded that the superheater concept can provide a more efficient way of using the natural gas.

Although the coupling with gas turbines shows a more significant improvement, the number of gas turbine units to achieve that performance also needs to be considered in the cost analysis. Furthermore, having both nuclear power plant and gas turbine in the same area might be difficult to justify in terms of space and safety issues. From this point of view, the conventional gas burner scheme seems to be more favourable option due to its simplicity, and thus easier to implement. Another challenge that needs to be addressed is the existing capacity of the commercial steam turbines. There is currently no single shaft steam turbine that can produce about 2,000 MWe and the cost of having more than one turbine in the plant would need to be considered in the cost estimates. Therefore, this analysis was extended to consider a smaller power nuclear unit so that the total power plant output at full capacity would be within the limits of current commercially available steam turbines. The results of this analysis are presented in the following section.

Another modification that can be made to further increase the thermodynamic efficiency of LWR is by reheating the exhaust steam of the HP turbine before it enters the LP turbine. The steam cycle flow diagram of the AP1000 with the conventional superheater and additional reheater is shown in Fig. 4. The thermodynamic parameters of this configuration scheme are presented in Table 4 and its T-s diagram is displayed in Fig. 5. As previously, the state point numbers in Fig. 5 correspond to locations specified in Fig. 4.

Fig. 4. AP1000 steam cycle with superheater and reheater flow diagram.

Table 4. Thermodynamic Analysis Results of AP1000 with Superheater and Reheater

Fig. 5. T-s diagram of AP1000 steam cycle with superheater and reheater.

The operating pressure at which the reheating process takes place is set to be equal to that at the exhaust of the HP Turbine of the other cases, while the reheat steam temperature is set at the temperature which optimizes the expansion process in the LP Turbine by maximizing the amount of heat that can be converted to electricity, minimizing the condenser duty, and maintaining the safe operation of the turbine. Table 4 shows that installing additional reheater in the steam cycle can further improve the thermal efficiency of the cycle to $36.59 \%$. This is similar to the previous concept (gas burner without reheating), although the total thermal efficiency improvement is less significant compared to fossil fuel technology, this concept 
has high fossil fuel cycle efficiency (45\%), which implies that this concept can provide more efficient way to burn the natural gas.

\section{SMR with Superheater Concept}

As mentioned above, there is no sufficiently large single shaft steam turbine commercially available that can produce more than 2,000 MWe at the moment. Therefore, the superheater concept might be more valuable if it is coupled with the Small Modular Reactor (SMR) instead of a large reactor. The reference reactor used for this analysis is the mPower design, which is a 180 MWe PWR developed by B\&W. The reference reactor used for this study is a twin pack of the mPower reactor producing about 1,060 MWt and $360 \mathrm{MWe}$ [12]. The steam cycle analysis shows that the thermal efficiency of the SMR considered in this study is $33.41 \%$. Similar to the AP1000 analysis, both the CCGT coupling concept and the gas burner concept were studied in the context of SMR coupling scheme and the results are shown in Table 5 .

Table 5. Thermodynamic Analysis Results of SMR with Superheater

Table 5 shows that the cycle efficiency can be improved from $33.41 \%$ to $44.99 \%$ (CCGT) or $35.50 \%$ (gas burner). By using CCGT coupling scheme, significant improvement in the thermal efficiency can be achieved with only 2 units of gas turbine instead of 6 units for the AP1000. A modification of the gas burner concept with additional reheater to further improve the thermal efficiency is also considered. It is shown that by installing additional reheater, the thermal efficiency of the SMR considered can increase further to $35.82 \%$. In terms of fossil fuel cycle efficiency, it is shown that only the CCGT scheme can provide a better cycle efficiency compared to the existing stand-alone gas turbine type technology with thermal efficiency of approximately $40 \%$.

\section{Load Following Operation}

It has been mentioned earlier that the motivation to increase thermal efficiency in PWR is the necessity for developing a power system with load following capability. The results of the thermodynamic analysis in the previous sections show that for the large reactor, the superheater using gas burner concept with reheating scheme is the most favourable option to increase the thermal efficiency of the nuclear reactor. This is because it may potentially prove challenging to couple the reactor with 6 gas turbine units even though it would offer a better thermodynamic performance. Table 6 demonstrates that the hybrid system of the AP1000 coupled with superheater and reheater using gas burner scheme has the potential to develop the load following capability without affecting the nuclear reactor operation (power output). It has been mentioned that nuclear power has higher capital cost and therefore the ability to follow the load while maintaining the reactor operation at its full capacity has very high economical value. It should be noted that the results shown in Table 6 correspond to just one of many possible options of load following design for the hybrid system. Table 6 shows that it is possible for the hybrid system to operate in a load following regime between $65 \%$ and $100 \%$ of its full capacity while keeping the nuclear reactor power output at its maximum at all times. Table 6 also shows that the hybrid system can operate in a load following regime while maintaining its cycle efficiency above the stand-alone nuclear power plant. In terms of designing the load following scheme, it is necessary for the operating conditions such as superheated steam temperature and reheated steam temperature to be optimized in order to get the highest achievable cycle efficiency. Such optimisation is planned to be performed in future studies. The T-s diagram for each load configuration are shown in Fig. 6. 
Table 6. Load Following Design for the AP1000 with Superheater Concept

Fig. 6. T-s diagram of load following operation of AP1000 with superheater and reheater.

Similar to the large reactor, the hybrid system of SMR with superheater and reheater scheme also has the potential for the load following capability as shown in Table 7. The table shows that the hybrid system of SMR with superheater and reheater can reduce its operating load down to $65 \%$ while maintaining $100 \%$ of reactor core power. However, it is also observed from Table 7 that the operation below $85 \%$ load capacity will reduce its cycle efficiency below the stand-alone nuclear system (approximately 33.41\%). Further investigation is needed to decide on the most efficient way for the hybrid system to follow the load below $85 \%$ load capacity as it is unclear how the cycle efficiency of the hybrid system will behave if the reactor core power is reduced. The economic trade off analysis of the cycle efficiency will also be a subject for future studies.

Table 7. Load Following Design for the SMR with Superheater Concept

\section{Other Considerations for the Implementation of the Hybrid System}

From the safety point view, the implementation of this hybrid concept using gas burner should not raise any additional concerns as it is just a matter of installing a relatively simple additional equipment outside the reactor containment which will not be in physical contact with primary water coolant. If the NPP is combined with the gas turbine (CCGT concept), more equipment will be needed and operational feedbacks of the secondary circuit to the primary one will likely to be more complex, possibly requiring additional safety related studies.

The main driver for the presented concepts is clearly the economics. Combining NPP with the conventional gas burner to superheat the steam would increase the plant thermal efficiency and allow flexible load following operation. The economic benefits are expected to be the result of relatively small incremental costs of adding a gas burner compared to the capital costs of the NPP. This is while the amount of electric power generated by the hybrid system could be almost doubled compared to the power output of a conventional NPP. However, since natural gas is used as the heat source for the superheater, the sensitivity of the electricity price to the natural gas price volatility needs to be taken into consideration in the economic analysis of the hybrid system.

Although the addition of fossil fuel superheater to the NPP has shown an improvement in its thermodynamic performance, an area that requires further study is the limitation on the capacity of existing commercial steam turbines. Although it is possible to use more than one steam turbine in the plant, the incremental costs related to the equipment siting, operation and maintenance need to be considered, which might result in an increased cost of electricity. Nevertheless, this option is still worth considering if the implementation of the hybrid system is envisaged in an existing operating nuclear power plant. If the concept is applied to a new reactor, the implementation in an SMR could be more favourable than in a large reactor. SMRs have smaller power output compared to the large reactors and, therefore, the amount of combined total power generated by the reactor and the gas burner would still be within the limits of existing conventional steam turbine technology. This is in addition to a number of other attractive features of SMRs related to their economics - such as smaller total capital investment required and shorter construction schedule. 


\section{Conclusion and Further Work}

The preliminary study described in this paper shows that coupling of the nuclear power plant with the conventional fossil fuel superheater can improve the thermodynamic performance and add load following capability to the system. There are several options for the coupling scheme. Two of them are considered in this study: using exhaust gas from the gas turbines (CCGT concept) and using the conventional gas burner. The thermal efficiency of the AP1000 can be improved from $30.23 \%$ to $45.78 \%$ (CCGT), $35.66 \%$ (gas burner), or $36.59 \%$ (gas burner with reheating). When this concept is applied to the SMR, the thermal efficiency of the SMR can be improved from 33.41\% to 44.99\% (CCGT), 35.50\% (gas burner), or $35.82 \%$ (gas burner with reheating). Although this increase might not seem to be significant, it can potentially improve the competitiveness of nuclear energy compared to the fossil fueled power plants which have thermal efficiency of $36-48 \%$. A detailed analysis is planned to be performed in order to quantify the hypothesised economic advantages.

Although the CCGT scheme shows more significant improvement in the thermal efficiency compared to the gas burner concept even with the addition of reheater, it might be premature to conclude that it is a better option economically. A thorough economic assessment needs to be done in order to establish conclusively which scheme has the most potential benefit thermodynamically and economically considering realistic market conditions. This assessment will be the next step of our study.

The load following scenario can be developed for the coupling system of PWR with conventional fossil fuel superheater. For a large reactor, the coupling of AP1000 with superheater and reheater can be designed to have flexible operation in the range $65 \%-100 \%$ load without affecting the reactor operation. In addition, the hybrid system can achieve such load following range while maintaining its cycle efficiency above the stand alone nuclear system. In the case of SMR, the coupling of SMR with superheater and reheater can also be designed to have flexible operation down to $65 \%$ of the full power load while maintaining $100 \%$ of the reactor core power. However, below the $85 \%$ of nominal load, the cycle efficiency will drop below the stand-alone nuclear system. Further investigation on the most efficient way to follow the load below $65 \%$ capacity for the large reactor and $85 \%$ capacity for the SMR is needed. This will be the subject of future studies as it is desirable for a nuclear power plant to be able following the load in a wider range of power levels.

There are a number of challenges to be tackled in terms of feasibility of coupling NPP with conventional superheater. One of them is the power rating of the existing commercial steam turbines. Therefore, further study is needed to ensure that this coupling scheme is feasible and makes sense economically.

\section{Nomenclature}

$h \quad$ specific enthalpy $(\mathrm{kJ} / \mathrm{kg})$

$\dot{m} \quad$ mass flow rate $(\mathrm{kg} / \mathrm{s})$

$P \quad$ power $(\mathrm{kW})$

$Q \quad$ heat $(\mathrm{kJ})$

$S \quad$ specific entropy $(\mathrm{kJ} / \mathrm{kg} \mathrm{K})$

$T$ temperature $\left({ }^{\circ} \mathrm{C}\right)$

$W \quad$ work $(\mathrm{kJ} / \mathrm{s})$

$\eta \quad$ efficiency (\%) 


\section{Acknowledgements}

The first author acknowledges the support from the Indonesia Endowment Fund for Education (LPDP). 


\section{References}

[1] Forsberg CW, Conklin JC. A nuclear-fossil combined-cycle power plant for base-load and peak electricity. Transactions-American Nuclear Society 2007;96:683-684.

[2] Ko YC, Kazimi M. Conceptual Design of an Annular-Fueled Superheat Boiling Water Reactor. MIT-ANP-TR-130; Oct., 2010.

[3] Florido PE, Bergallo JE, Clause A. Economics of combined nuclear-gas power generation. Technical Note. Nuclear Engineering and Design 2000;195:109-115.

[4] Darwish MA, Al Awadhi FM, Bin Amer AO. Combining the nuclear power plant steam cycle with gas turbines. Energy 2010;35:4562-4571.

[5] Zaryankin A, Lyskov M, Arianov S, Rogalev A. Super powerful steam superheaters and turbines for hybrid nuclear power plants. Journal of Power Technologies 2011;91 (4):191-197.

[6] Westinghouse. The Westinghouse AP1000 Advanced Nuclear Plant, Plant description. Westinghouse Electric Co., LLC; 2003.

[7] Ion D., Codrut P. D. Efficiency Assessment of Condensing Steam Turbine. Advances in Environment, Ecosystems, and Sustainable Tourism, ISBN: 978-1-61804-195-1, 203208.

[8] Holmgren M. X Steam Tables, Excel macros, IF-97 Steam Tables, http://www.Xeng.com/; 2007 [accessed 10.10.2015].

[9] IAPWS. Revised Released on the IAPWS Industrial Formulation 1997 for the Thermodynamic Properties of Water and Steam. The International Association for the Properties of Water and Steam. Lucerne, Switzerland; August, 2007.

[10] Siemens. Siemens Gas Turbine SGT5-4000F, Advanced performance. Siemens AG; 2008.

[11] Lemmon EW, Jacobsen RT, Penoncello SG, Friend DG. Thermodynamic Properties of Air and Mixtures of Nitrogen, Argon, and Oxygen from 60 to $2000 \mathrm{~K}$ at Pressures to 2000 MPa. J. Phys. Chem. Ref. Data 2000;29 (3):331-385.

[12] Temple R. Generation mPower, B\&W mPower ${ }^{T M}$ Program. IAEA SMR Technical Meeting. Chengdu, China; September $3^{\text {rd }}, 2013$. 
Table 1. Steam (Water) Condition in Each Point of AP1000 Steam Cycle

\begin{tabular}{|c|c|c|c|c|c|c|}
\hline Point & m (kg/s) & $\mathbf{P}$ (bar) & $\mathbf{T}\left({ }^{\circ} \mathrm{C}\right)$ & $\mathbf{x}(-)$ & h (kJ/kg) & $\mathrm{s}(\mathrm{kJ} / \mathrm{kg} \mathrm{K})$ \\
\hline 1 & 1886.00 & 55.50 & 271.00 & 1.00 & 2791.3 & 5.93 \\
\hline 2 & 1800.00 & 55.00 & 271.00 & 1.00 & 2794.5 & 5.94 \\
\hline 3 & 1260.00 & 10.50 & 182.02 & 0.88 & 2541.1 & 6.05 \\
\hline 4 & 1200.00 & 9.50 & 251.00 & 1.00 & 2947.3 & 6.96 \\
\hline 5 & 1000.00 & 0.10 & 45.81 & 0.89 & 2322.7 & 7.33 \\
\hline 6 & 1100.00 & 0.10 & 44.00 & 0.00 & 184.3 & 0.63 \\
\hline 7 & 1100.00 & 30.00 & 44.28 & 0.00 & 188.0 & 0.63 \\
\hline 8 & 1100.00 & 30.00 & 67.82 & 0.00 & 286.3 & 0.93 \\
\hline 9 & 1100.00 & 30.00 & 91.48 & 0.00 & 385.5 & 1.21 \\
\hline 10 & 1200.00 & 30.00 & 116.81 & 0.00 & 492.2 & 1.49 \\
\hline 11 & 1200.00 & 30.00 & 138.26 & 0.00 & 583.4 & 1.72 \\
\hline 12 & 1972.00 & 30.00 & 192.02 & 0.00 & 817.3 & 2.25 \\
\hline 13 & 1972.00 & 60.00 & 192.64 & 0.00 & 821.4 & 2.25 \\
\hline 14 & 1972.00 & 60.00 & 226.70 & 0.00 & 975.5 & 2.57 \\
\hline 15 & 60.00 & 10.50 & 182.02 & 0.88 & 2541.1 & 6.05 \\
\hline 16 & 50.00 & 3.50 & 156.97 & 1.00 & 2772.4 & 7.04 \\
\hline 17 & 50.00 & 3.00 & 144.27 & 1.00 & 2748.7 & 7.05 \\
\hline 18 & 50.00 & 1.50 & 111.35 & 0.98 & 2647.9 & 7.11 \\
\hline 19 & 50.00 & 0.50 & 81.32 & 0.94 & 2504.2 & 7.20 \\
\hline 20 & 100.00 & 0.10 & 81.32 & 1.00 & 2651.8 & 8.35 \\
\hline 21 & 501.41 & 30.00 & 233.86 & 0.64 & 2158.9 & 2.65 \\
\hline 22 & 1972.00 & 60.00 & 209.85 & 0.00 & 898.5 & 2.42 \\
\hline 23 & 90.00 & 30.00 & 233.86 & 0.94 & 2696.9 & 5.98 \\
\hline 24 & 90.00 & 30.00 & 233.86 & 0.94 & 2696.9 & 5.98 \\
\hline 25 & 86.00 & 30.00 & 269.97 & 1.00 & 2914.7 & 6.40 \\
\hline 26 & 360.00 & 30.00 & 233.86 & 0.35 & 1629.6 & 3.87 \\
\hline 27 & 176.00 & 30.00 & 233.86 & 0.49 & 1885.4 & 2.65 \\
\hline 28 & 100.00 & 3.00 & 133.53 & 0.01 & 572.9 & 1.70 \\
\hline 29 & 86.00 & 55.00 & 271.00 & 1.00 & 2794.5 & 5.94 \\
\hline 30 & 360.00 & 30.00 & 233.86 & 0.94 & 2696.9 & 5.98 \\
\hline
\end{tabular}

Table 2. Steam Cycle Equipment Efficiencies [7]

\begin{tabular}{|c|c|}
\hline Variable & Value \\
\hline$\eta_{\text {Turbine }}$ & $84 \%$ \\
\hline$\eta_{\text {Pump }}$ & $82 \%$ \\
\hline$\eta_{\text {Generator }}$ & $98 \%$ \\
\hline
\end{tabular}


Table 3. Thermodynamic Analysis Results of AP1000 with Superheater

\begin{tabular}{|l|r|r|r|}
\hline \multicolumn{1}{|c|}{ Parameter } & \multicolumn{1}{c|}{$\begin{array}{c}\text { No } \\
\text { Superheater }\end{array}$} & \multicolumn{1}{c|}{$\begin{array}{c}\text { CCGT } \\
\text { Scheme }\end{array}$} & \multicolumn{1}{c|}{$\begin{array}{c}\text { Gas Burner } \\
\text { Scheme }\end{array}$} \\
\hline Number of Gas Turbine Unit & - & 6 & - \\
\hline HP turbine inlet temp. $\left({ }^{\circ} \mathrm{C}\right)$ & 271 & 530 & 600 \\
\hline $\mathrm{W}_{\text {HP turbine }}(\mathrm{MWt})$ & 372.0 & 784.8 & 865.4 \\
\hline $\mathrm{W}_{\text {LP turbine }}(\mathrm{MWt})$ & 680.3 & $1,138.2$ & $1,221.3$ \\
\hline $\mathrm{W}_{\text {tot }}(\mathrm{MWt})$ & $1,052.3$ & $1,923.0$ & $2,086.7$ \\
\hline Nuclear Power generated (MWe) & $1,031.3$ & $1,884.5$ & $2,045.0$ \\
\hline Additional Power $(\mathrm{MWe})$ & - & 2,016 & - \\
\hline Total Power $(\mathrm{MWe})$ & $1,031.3$ & $3,900.5$ & $2,045.0$ \\
\hline Additional Heat Req. $(\mathrm{MWt})$ & - & $5,103.8$ & $2,318.0$ \\
\hline Reactor Thermal Power $(\mathrm{MWt})$ & $3,416.6$ & $3,416.6$ & $3,416.6$ \\
\hline Increment of Power $(\%)$ & - & 277.66 & 98.00 \\
\hline Fossil Fuel Cycle Eff. $(\%)$ & - & 56.19 & 43.66 \\
\hline Total Cycle Efficiency $(\%)$ & 30.23 & 45.78 & 35.66 \\
\hline
\end{tabular}

Table 4. Thermodynamic Analysis Results of AP1000 with Superheater and Reheater

\begin{tabular}{|l|r|c|}
\hline \multicolumn{1}{|c|}{ Parameter } & \multicolumn{2}{c|}{ Value } \\
\hline HP turbine inlet temp. & 600 & ${ }^{\circ} \mathrm{C}$ \\
\hline Reheat steam temp. & 450 & ${ }^{\circ} \mathrm{C}$ \\
\hline $\mathrm{W}_{\text {HP turbine }}$ & 865.4 & $\mathrm{MWt}$ \\
\hline $\mathrm{W}_{\mathrm{LP} \text { turbine }}$ & $1,336.8$ & $\mathrm{MWt}$ \\
\hline $\mathrm{W}_{\text {tot }}$ & $2,202.1$ & $\mathrm{MWt}$ \\
\hline Nuclear Power generated & $2,158.1$ & $\mathrm{MWe}$ \\
\hline Additional Heat Req. & $2,481.3$ & $\mathrm{MWt}$ \\
\hline Reactor Thermal Power & $3,416.6$ & $\mathrm{MWt}$ \\
\hline Increment of Power & 108.95 & $\%$ \\
\hline Fossil Fuel Cycle Eff. & 45.35 & $\%$ \\
\hline Total Cycle Efficiency & 36.59 & $\%$ \\
\hline
\end{tabular}


Table 5. Thermodynamic Analysis Results of SMR with Superheater

\begin{tabular}{|c|c|c|c|c|}
\hline Parameter & $\begin{array}{c}\text { No } \\
\text { Superheater }\end{array}$ & $\begin{array}{c}\text { CCGT } \\
\text { Scheme }\end{array}$ & $\begin{array}{l}\text { Gas Burner } \\
\text { Scheme }\end{array}$ & $\begin{array}{c}\text { Gas Burner } \\
\text { with } \\
\text { Reheating } \\
\end{array}$ \\
\hline $\begin{array}{l}\text { Number of Gas Turbine } \\
\text { Unit }\end{array}$ & - & 2 & - & - \\
\hline $\begin{array}{l}\text { HP turbine inlet temp. } \\
\left({ }^{\circ} \mathrm{C}\right)\end{array}$ & 299.44 & 530 & 600 & 600 \\
\hline $\mathrm{W}_{\mathrm{HP} \text { turbine }}(\mathrm{MWt})$ & 122.3 & 225.6 & 248.9 & 248.9 \\
\hline $\mathrm{W}_{\mathrm{LP} \text { turbine }}(\mathrm{MWt})$ & 239.0 & 342.6 & 367.5 & 402.5 \\
\hline $\mathrm{W}_{\text {tot }}(\mathrm{MWt})$ & 361.3 & 568.2 & 616.4 & 651.4 \\
\hline $\begin{array}{l}\text { Nuclear Power } \\
\text { generated (MWe) }\end{array}$ & 354.1 & 556.9 & 604.1 & 638.3 \\
\hline $\begin{array}{l}\text { Additional Power } \\
\text { (MWe) }\end{array}$ & - & 576.0 & - & - \\
\hline Total Power (MWe) & 354.1 & $1,132.9$ & 604.1 & 638.3 \\
\hline $\begin{array}{l}\text { Additional Heat Req. } \\
(\mathrm{MWt})\end{array}$ & - & $1,458.2$ & 641.9 & 722.2 \\
\hline $\begin{array}{l}\text { Reactor Thermal Power } \\
(\mathrm{MWt})\end{array}$ & $1,060.0$ & $1,060.0$ & $1,060.0$ & $1,060.0$ \\
\hline Increment of Power (\%) & - & 219.93 & 70.60 & 80.27 \\
\hline $\begin{array}{l}\text { Fossil Fuel Cycle Eff. } \\
(\%)\end{array}$ & - & 53.41 & 38.95 & 39.35 \\
\hline $\begin{array}{l}\text { Total Cycle Efficiency } \\
(\%)\end{array}$ & 33.41 & 44.99 & 35.50 & 35.82 \\
\hline
\end{tabular}

Table 6. Load Following Design for the AP1000 with Superheater Concept

\begin{tabular}{|c|c|c|c|c|}
\hline $\begin{array}{c}\text { Power Output } \\
(\boldsymbol{\%} \text { of } \\
\text { nominal) }\end{array}$ & $\begin{array}{c}\text { HP Turbine Inlet } \\
\text { Temperature } \\
\left(\mathbf{(}^{\mathbf{C}} \mathbf{C}\right)\end{array}$ & $\begin{array}{c}\text { Reheated Steam } \\
\text { Temperature } \\
\mathbf{(} \mathbf{C})\end{array}$ & $\begin{array}{c}\text { Total Power } \\
\text { Generated } \\
(\mathbf{M W e})\end{array}$ & $\begin{array}{c}\text { Total Cycle } \\
\text { Efficiency } \\
(\boldsymbol{\%})\end{array}$ \\
\hline 100 & 600 & 450 & $2,158.1$ & 36.59 \\
\hline 90 & 550 & 350 & $1,946.3$ & 34.88 \\
\hline 80 & 400 & 320 & $1,728.2$ & 32.97 \\
\hline 70 & 350 & 195 & $1,514.9$ & 32.17 \\
\hline 65 & 271 & 192 & $1,424.2$ & 31.08 \\
\hline
\end{tabular}

Table 7. Load Following Design for the SMR with Superheater Concept

\begin{tabular}{|c|c|c|c|c|}
\hline $\begin{array}{c}\text { Power Output } \\
(\boldsymbol{\%} \text { of } \\
\text { nominal) }\end{array}$ & $\begin{array}{c}\text { HP Turbine Inlet } \\
\text { Temperature } \\
\left(\mathbf{(}^{\mathbf{C}}\right)\end{array}$ & $\begin{array}{c}\text { Reheated Steam } \\
\text { Temperature } \\
\left(\mathbf{}^{\mathbf{C}}\right)\end{array}$ & $\begin{array}{c}\text { Total Power } \\
\text { Generated } \\
(\mathbf{M W e})\end{array}$ & $\begin{array}{c}\text { Total Cycle } \\
\text { Efficiency } \\
(\boldsymbol{\%})\end{array}$ \\
\hline 100 & 600 & 450 & 638.3 & 35.82 \\
\hline 90 & 550 & 350 & 575.2 & 34.41 \\
\hline 85 & 500 & 320 & 545.9 & 33.59 \\
\hline 80 & 400 & 320 & 511.6 & 32.54 \\
\hline 70 & 350 & 200 & 449.8 & 31.60 \\
\hline 65 & 271 & 192 & 408.1 & 30.64 \\
\hline
\end{tabular}




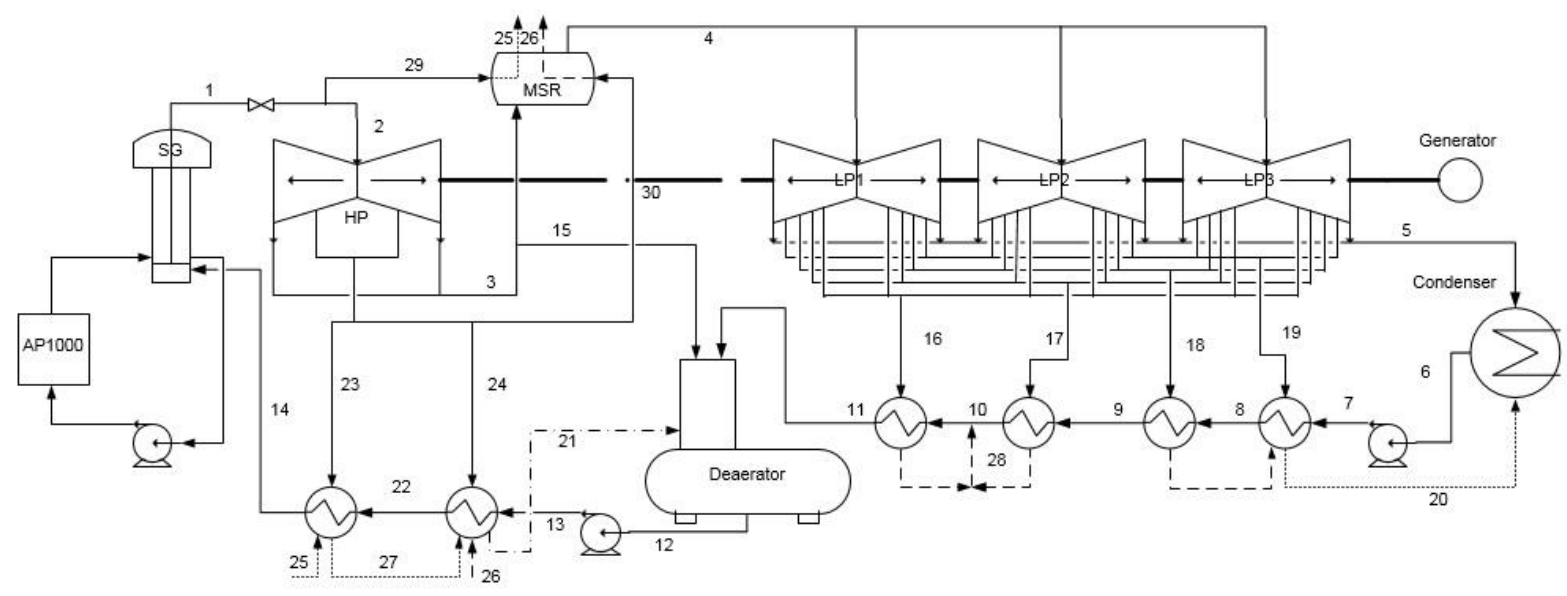

Fig. 1. AP1000 steam cycle flow diagram.

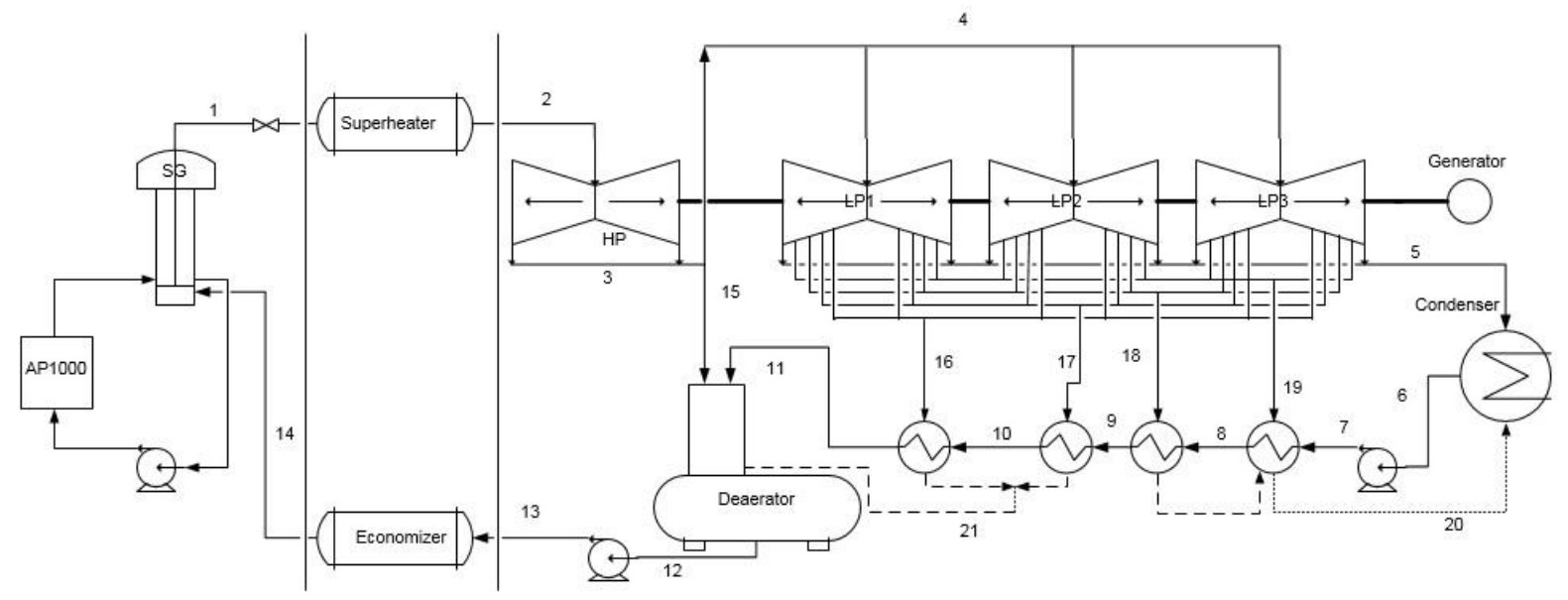

Fig. 2. AP1000 steam cycle with superheater flow diagram. 

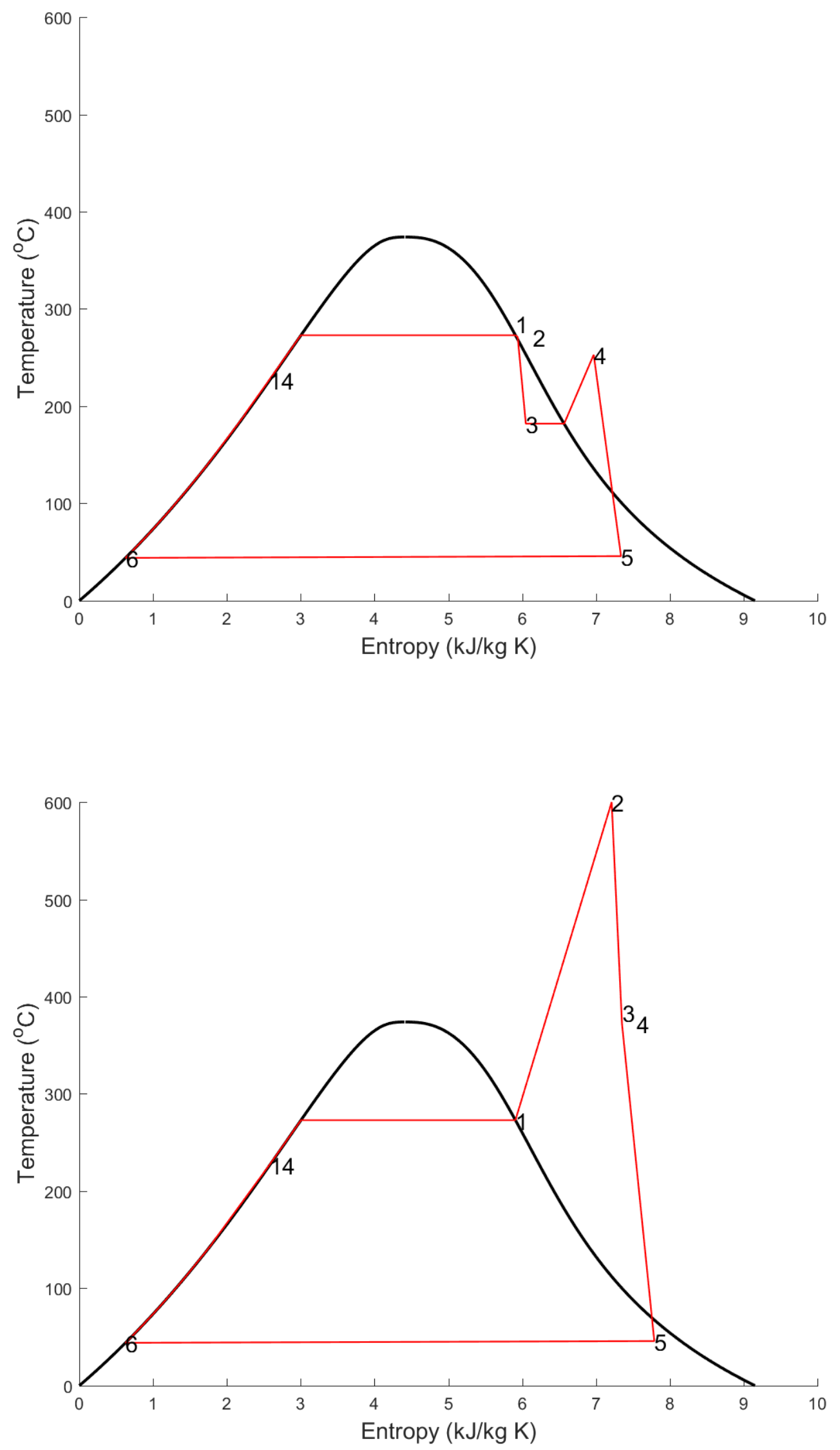

Fig. 3. T-s diagram of AP1000 steam cycle: (a) without superheater; (b) with superheater. 


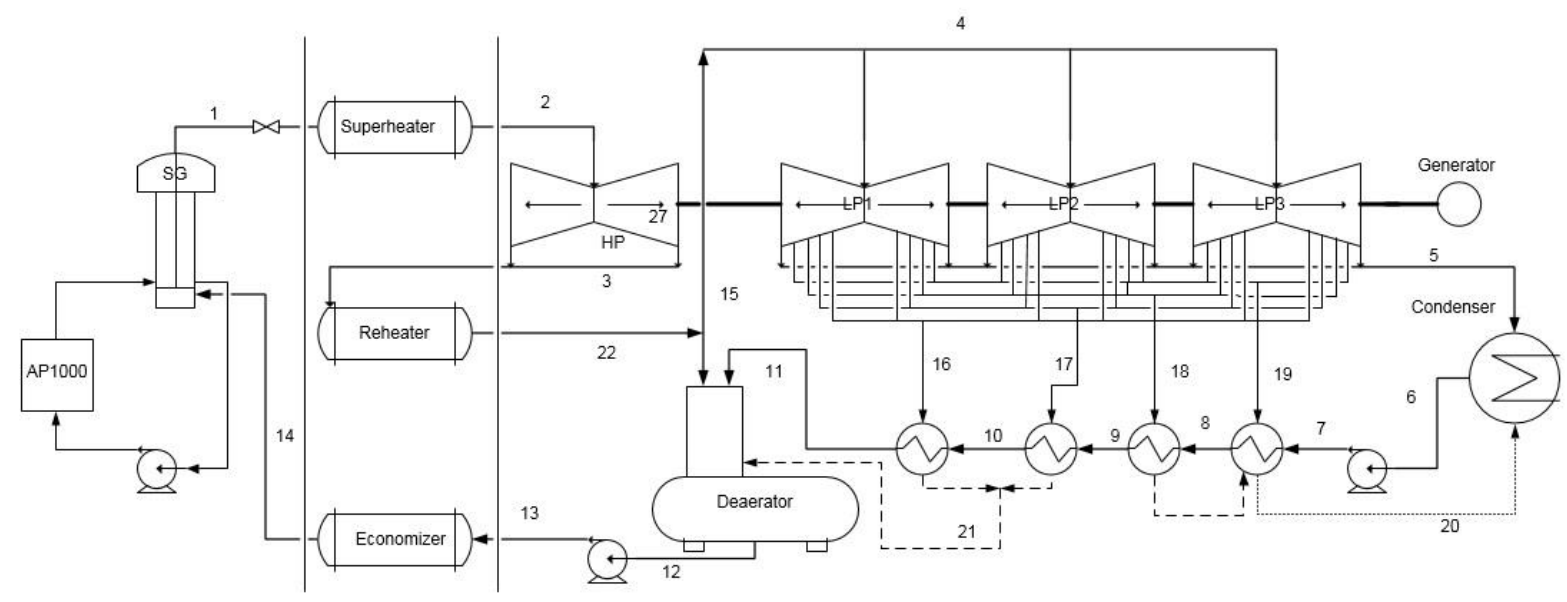

Fig. 4. AP1000 steam cycle with superheater and reheater flow diagram.

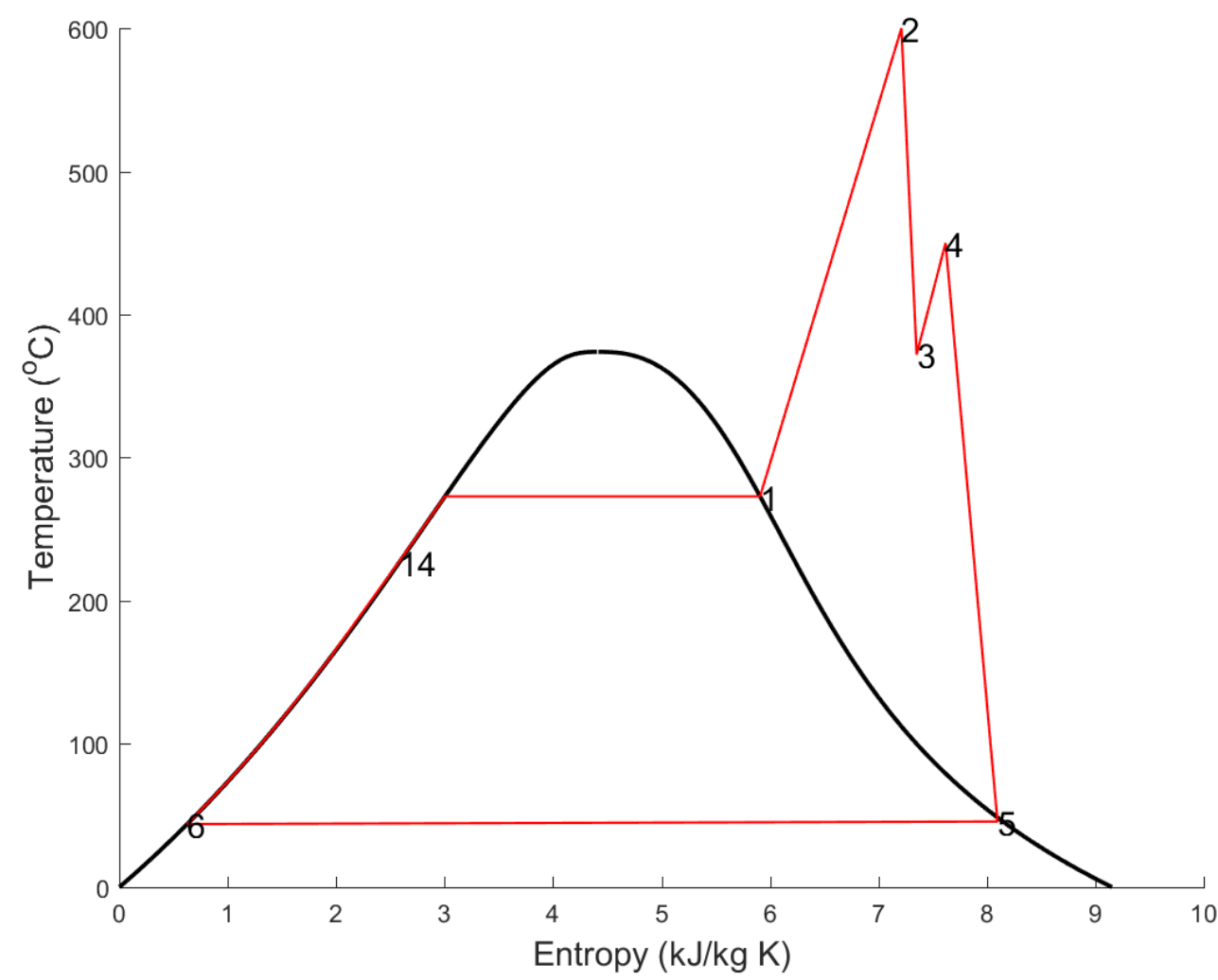

Fig. 5. T-s diagram of AP1000 steam cycle with superheater and reheater. 


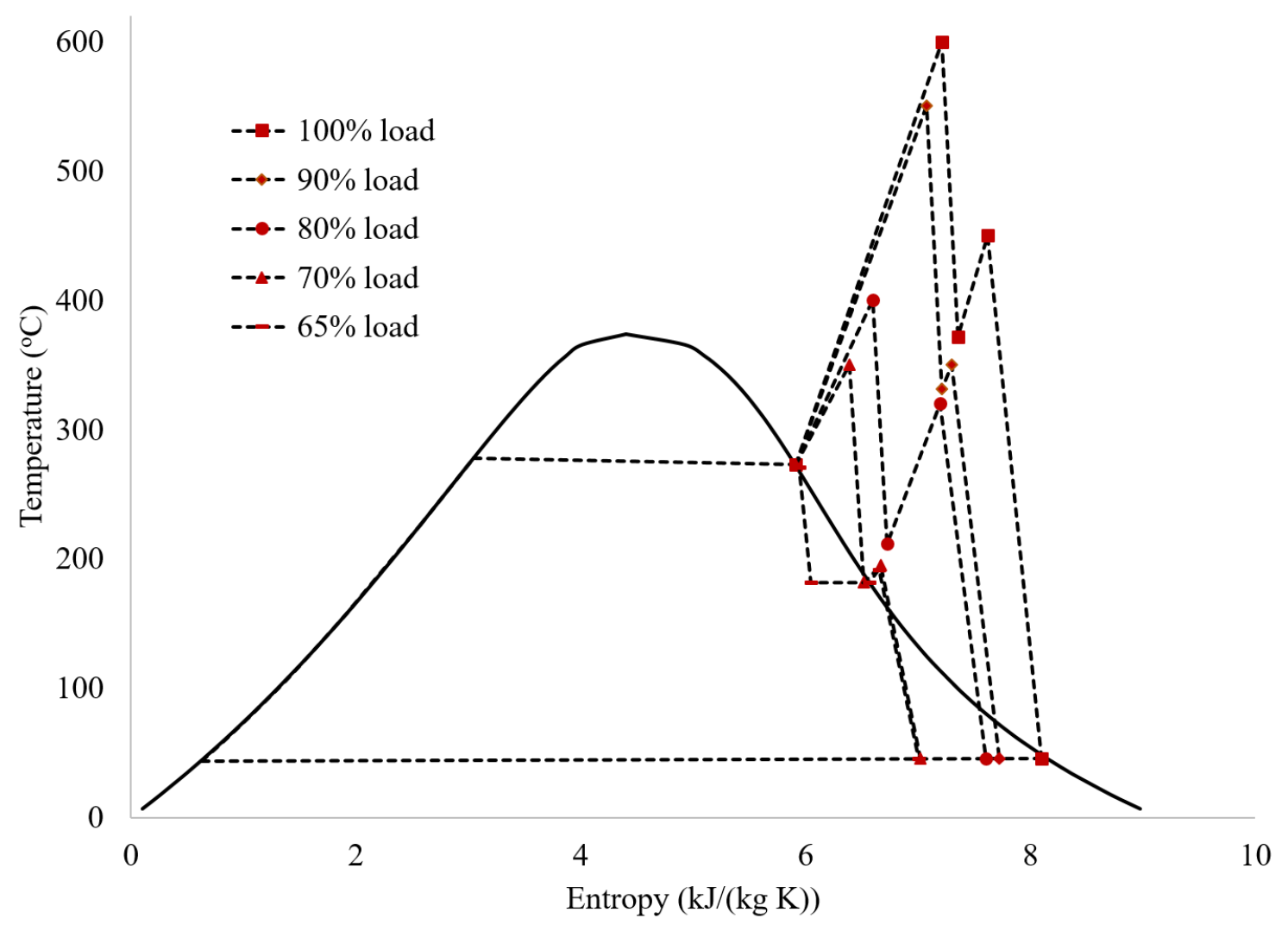

Fig. 6. T-s diagram of load following operation of AP1000 with superheater and reheater. 